\title{
THE ROYAL SOCIETY OF EDINBURGH
}

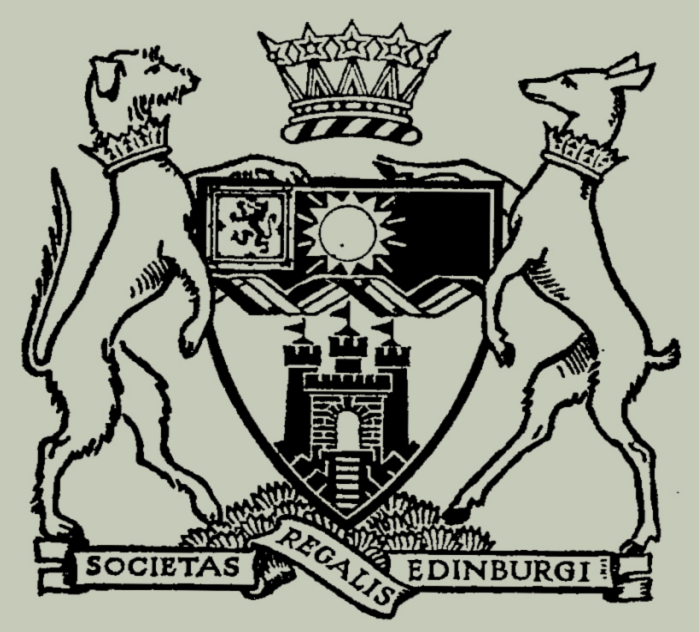

\section{TRANSACTIONS}

A Stratigraphical Revision of the Old Red Sandstone of North-eastern Caithness

By R. NOWELL DONOVAN, RICHARD J. FOSTER and T. STANLEY WESTOLL

PUBLISHED BY THE ROYAL SOCIETY OF EDINBURGH 22 GeORge Street, EDINBURGH, EH2 2PQ Price: $£ 1 \cdot 50$ : (\$5.00) 